\title{
LA EXPERIENCIA AUTOBIOGRÁFICA DE ALBERTINE SARRAZIN*
}

\author{
Antonio Bueno García** \\ Universidad de Valladolid
}

\begin{abstract}
RESUMEN. La obra de Albertine Sarrazin interesa a la crítica por esa profesión de fe que hace de estilo estrictamente autobiográfico y por la experiencia que revela de la prisión. Todos sus escritos (diario intimo, cartas -y también billetes clandestinos-o novelas) son portadores de una estructura propia y obedecen a necesidades personales y a posibilidades del medio (en el régimen penitenciario está prohibida toda escritura salvo la autorizada). En nuestra tesis, Las formas de la autobiografía en Albertine Sarrazin, ofrecemos una visión más profunda con la inclusión además de otros géneros.

RÉSUMÉ. L'oeuvre d'Albertine Sarrazin intéresse la critique pour cette profession de foi qu'elle fait de style strictement autobiographique et pour l'experience qu'elle révèle de la prision. Tous ses écrits (journal intime, lettres - et aussi "biftons"-ou romans) sont porteurs d'une structure propre et obéissent aux besoins personnelles et aux possibilités du milieu (l'écriture autre que l'autorisée étant interdite en régime penitentiare). Une vision plus approfondie -contenant encore d'autres genres-est donnée dans notre thèse, Las formas de la autobiografía en Albertine Sarrazin.
\end{abstract}

La obra de Albertine Sarrazin nos parece especialmente interesante, y no ya sólo por el pretendido ${ }^{1}$ carácter autobiográfico de todos sus escritos -numerosos si tenemos en cuenta lo breve que fue su vida: apenas contaba treinta años cuando se extinguió- sino también por la singular experiencia que hace de la prisión, a la que se vio condenada durante casi un tercio de su vida.

La experiencia de la reclusión nos debe llevar en la mayoría de las casos a un análisis especial de la situación y del comportamiento del escritor y debe ser considerada como singular en la medida que en prisión todo adquiere una resonancia y un significado especiales:

"les mots prononcés intra-muros ont beaucoup plus de portée que les discours faits dehors lorsque la vie nous prend et nous saoule [sic]." 2

* Recibido el 6 de octubre de 1993.

** Doctor en Filología Francesa, Profesor Asociado del Departamento de Filología Francesa de la Universidad de Valladolid en el Colegio Universitario de Soria.

1. Es necesario por nuestra parte tomar toda serie de precauciones y marcar una distancia objetiva ante la confesión del autor y el resultado estético de su obra.

2. Albertine Sarrazin, Biftons de prison. París: Pauvert, 1977. 
El paso por la prisión representa inevitablemente una interrupción en la vida del individuo, un viaje por la muerte, un fracaso en su existencia.

Las ideas de espacio y tiempo resultan seriamente dañadas y aparecen también transgredidas en el mundo de la escritura: el espacio de la celda, exiguo y tenebroso, resulta ser el del escritor; el tiempo deja de tener el valor relativo del paso de la existencia (normal) y se confunde con las acciones del día, cuando no se sumerge en un profundo e interminable letargo,

"La prison est une perpétuelle, une atroce disharmonie."3

Es cierto que esta experiencia es vivida por cada persona de manera completamente distinta y mientras Genet por ejemplo magnifica los muros y la actitud del delincuente y Boudard ironiza humorísticamente con los personajes de la prisión, Albertine intenta continuamente la fuga, mítica, en la medida que no sólo consiste en escapar de una manera física a la reclusión sino también moral,

"Il faut que je termine la première peine; alors, autant me casser tout de suite, avant l'audience. Si je ne peux pas, je me casserai après, mais de toute façon je me casserai." 4

Gusdorf, que vio en la autobiografía un gesto de carácter "iniciático", un "símbolo", una "búsqueda de las profundidades del ser", donde el escritor libra un "combate contra su propia sombra y sus fantasmas", no podía imaginar hasta qué punto esa teoría resultaba válida en el caso del escritor encarcelado, que puede con más razón resultar desastrosamente vencido por tener aquí materialmente amenazada su identidad. La conquista de sí mismo le permitiría dar sentido a ese "yo" condenado, disgregado; reconciliarse consigo mismo y también a veces con la sociedad.

Fue Casanova quien además dijo:

"Si el prisionero es un hombre de letras que le den papel y pluma y su desgracia disminuirá en nueve décimas partes." 5

y Albertine quien también reconoció:

"En taule, la pitance littéraire est la meilleure."6

El régimen penitenciario no crea, sabemos, escritores -la vocación de Albertine era muy anterior-, pero sí puede explicar, creemos, ciertos comportamientos y reac-

3. Albertine Sarrazin, La Cavale. París: Pauvert, 1965.

4. Albertine Sarrazin, Idem.

5. Giacomo Casanova, Mi vida y mis amores (Título original: Histoire de ma vie). Planeta, 1984.

6. Albertine Sarrazin. Idem. 
ciones, ciertos "tics" de su escritura, como intentaremos demostrar a lo largo de estas páginas.

Si como decíamos, la totalidad de los escritos de Albertine pueden ser considerados como autobiográficos, es decir que responden a una serie de criterios ya reconocidos por todos como a ese "pacto" o compromiso entre escritor y lector del que habla Philippe Lejeune ${ }^{7}$ o a ese "acto literario" e incluso "jurídico" -según las terminologías de Elisabeth W. Bruss ${ }^{8}$ y de Béatrice Didier ${ }^{9}$ respectivamente-, no es menos cierto que todos deben ser considerados en su individualidad y con criterios diferenciados, por cuanto se da esa divergencia apuntada también por E. Bruss ${ }^{10}$ entre la "forma" o estructura física inmanente del texto y la "función" asignada a tal estructura.

Desde el punto de vista de la forma hemos de considerar aspectos como la disposición externa del manuscrito, la datación, etc. para diferenciar claramente unos géneros de otros. Desde el punto de vista de la función los textos difieren por su naturaleza estilística o de intriga sobre todo. El diario íntimo lleva implícita una amalgama de funciones -imposible de detallar aquí todas sus variaciones- citemos como más importante la de recomponer día a día la propia y amenazada existencia con la esperanza, como dice ella de "sauver quelques miettes du naufrage..."11 La diferencia esencial con la novela estriba en su propia mecánica de escritura, más anclada la primera en la realidad, con una distancia respecto al acontecimiento mucho más reducida y en general, como decíamos fechada. No podríamos sin embargo por ello hablar de objetividad o de sinceridad en el diario, pues sabemos cómo la imprecisión psicológica del primer instante puede alterar la verdad; por otra parte hay que contar con toda una serie de obstáculos morales que generalmente se oponen y, en el caso concreto de Albertine, con otros, como veremos, derivados del propio régimen penitenciario. El diario íntimo, por otra parte, se compone de una serie de reflexiones, sin trama bien precisa -a no ser la del propio desorden vital de su autor-y sin organización. Pertenece por ello al modo de lo "discontinuo": "la mémoire n'y joue pas ce rôle organique, organisateur qui caractérise le rythme de l'autobiographie"12. En la novela, por el contrario hay una parte de afabulación -que existe también en el diario, cómo no, pero en proporciones mínimas- una aventura que se consolida, un personaje que se convierte en tipo.

Tan alejado está en sus funciones el diario de la novela como de las cartas o de los "biftons" (billetes clandestinos intercambiados en prisión). Pudieran éstas parecerse,

7. Philippe Lejeune. Le pacte autobiographique. París: Seuil-Poétique, 1975.

(Este pacto, recordemos, no sólo se produce sobre lo que dice o deja de decir el autor, sino sobre la identidad entre autor, narrador y personaje en el texto propuesto).

8. Elisabeth W. Bruss, "L'autobiographie considerée comme acte littéraire", Poétique (1974) 17.

9. Béatrice Didier. Stendhal autobiographe. París: P.U.F., 1983.

("On dirait plutot de l'autobiographie qu'elle est un acte, d'abord au sens plein, mais aussi au sens juridique: un acte auquel le lecteur est sollicité d'apporter sa caution.)

10. Elisabeth W. Bruss. Op. cit.

11. Albertine Sarrazin. Journal de prison, 1959. París: Éditions Sarrazin, 1972.

12. Béatrice Didier. Le journal intime. París: P.U.F., 1976, p. 9. 
en cuanto van datadas (no es necesario ni deseable para los "biftons"), o llevan sus reflexiones sobre la jornada, pero éstas siempre tienen un claro destinatario (Julien, madrina, Gogois, editores, etc.) aunque, ¿cómo decir que el diario no?, siempre sentimos la presencia de un lector eventual, de Julien, mas éste queda siempre vago e impreciso. La carta hace siempre una llamada, espera una respuesta, es una comunicación a dos voces, a veces más en el caso de Albertine. La primera disposición de una carta o de un "bifton" -se explicarán después las diferencias- puede que sea la misma que en el diario, pero enseguida diverge. Las cartas cambian de tono y de naturaleza según el destinatario (cfr. las Lettres de la vie littéraire ${ }^{13}$ ), Albertine se modela a su propio gusto, según la idea que crea que de ella tengan, o de la que ella quiera que ellos se hagan. En el diario, por el contrario, Albertine tiende a expresar en la más estricta intimidad lo que le dicta su propia conciencia. La confesión puede que tenga consecuencias, lejanas, sobre su relación con los demás, pero no inmediatas. El grado de sinceridad tampoco es pues el mismo.

Es cierto también que esta relación, "forma-función", no es isomorfa, como dice E. Bruss y que puede darse el caso de que varias funciones pueden estar asignadas en una misma estructura y que la mayoría de las funciones pueden ser cumplidas por más de una forma. En los diarios de Albertine Sarrazin podemos encontrar fragmentos enteros que han sido reproducidos, sin cambiar un ápice, en sus novelas o en sus cartas, poemas que forman parte de estas últimas o de los "biftons" o cartas que forman parte del diario.

La manera de elaborar la propia autobiografía, la relación de forma y función, hace diferentes a unos escritores de otros. La propia experiencia personal, el espacio vital incluso en que se mueven también va a hacer diferente su experiencia. No es igual, que el autor se encuentre en prisión o en libertad, como demostraremos en nuestro trabajo; las consecuencias son muy distintas: los estímulos de la escritura, y, sin duda alguna, los de defensa del escritor frente a la realidad juegan un papel totalmente diferente.

El diario Albertine lo ha tenido siempre al lado, en secreto desde los catorce años, sólo viéndose interrumpido por el comienzo de la "aventura" o de la huida. A veces esta aventura también es "literaria" y su interrupción no debe ser interpretada más que como un trasvase de inspiración hacia sus libros. Sucede también que resulte confiscado por el personal de la prisión o como el de la segunda mitad de 1966 (constatado) que desaparezca "misteriosamente". Si no, ahí está, compañero fiel hasta sus últimos días, sirviendo de testigo de su azarosa vida.

En continua revuelta con la falsa moral de la sociedad, condenada por ella, la niña incomprendida, la joven fugitiva, la prisionera, la escritora, necesita respectivamente

13. Albertine Sarrazin, Lettres de la Vie Littéraire. París: Pauvert, 1974. 
del diario que la ilumine en las profundidades de lo desconocido, del final del camino, de la celda oscura o del libro para tener alguna posibilidad de salir, para recomponer ese espejo roto que es su vida. El diario íntimo, por ser el eco de la confesión más íntima, debe ser celosamente guardado y la joven del Pensionado ya expresa sus temores si llegara por casualidad a ser descubierto:

"Oh! Je serais si confuse si une seule fille de la pension pouvait lire ces lignes insipides! Ça n'a aucun sens je ne sais pas comment je peux m'obstiner à faire cet embrouillé manuscrit." 14

(...)

"Je me représente avec horreur ce qui se passerait si jamais la surveillante s'adressait à moi en ces termes. Il me semble que je préférerais quitter la pension que de livrer à des yeux moqueurs et apitoyés. "Apportez-moi..."15

La experiencia nos dice cómo los temores estaban más que justificados, pues cuántas veces no oiremos que tales o cuales páginas han sido para Albertine el principal argumento de su condena: En 1952, en su etapa del Bon Pasteur, su diario, sustraído a sus espaldas, fue utilizado por el psiquiatra para definirla como "perversa"; los "Carnets Verts" de su época de fuga en París sirvieron en el momento del juicio por el atraco para considerar a esta joven "cerebro de la operación" y, de nuevo, "perversa constitucional". Algún otro sería también confiscado en prisión posteriormente e incluso, en el momento de la publicación póstuma, nos consta más de un escrúpulo frente a ciertos pasajes comprometedores. Todo esto no parece menos normal ante unas hojas tan sinceras y cargadas de intimidad, en un tiempo en el que muchos testigos aún viven y que en ese ambiente aún no perdonan.

La lección de discreción y de agudo ingenio para disfrazar sus ideas parece que la aprendió bien Albertine en la prisión, y así, en sus cuadernos, vemos cómo no desvela, al menos con la claridad deseada, ningún hecho comprometedor para ella o para Julien.

Independientemente de este deseo de intimidad, de hermetismo y de desconfianza del diario íntimo frente a los demás, este pretendido monólogo egocéntrico no deja de transparentar la presencia de ese "otro" que la escucha, unas veces conocido: "mamá" (su madre a quien nunca vio), "madrina", Emilienne, Julien, etc. Otras desconocido: "vous", y siempre un lector anónimo que recoge la imprecación,

"Moi, je ne me sens, je ne me juge que par mon reflet sur les autres."16

El diario es en definitiva para ella, en prisión o en libertad, la imagen de ese "otro" que le dará la oportunidad de definirse.

14. "Cahiers de Pension", Journal de Fresnes. París: Presses-Pocket, 1983, p. 24.

15. Idem., p. 29

16. Lettres à Julien, 1958-1960, (8 de Septiembre de 1960), París: Pauvert, 1971. 
Por razón de interés, pasaremos por alto los cuadernos y carnés de la autora para detenernos un instante en ese singular diario redactado en las prisiones de Amiens y Soissons.

El "Times" o diario de Prisión de 1959, evita también dentro de lo que comentábamos evocar hechos comprometedores, pero alcanza un nivel óptimo de seguridad en la soledad y una espontaneidad encomiable en la escritura. "Times" podría muy bien designar a un periódico cotidiano, a no ser por la poca importancia que en él cobran los quehaceres y las noticias del día; es más bien, en este espacio donde los relojes también están prohibidos, el modo de marcar el tiempo de vida en la prisión, el tiempo confundiéndose aquí con la escritura. La prisionera escribe para poder asir con sus manos el tiempo (¡qué cuestión más infructuosa en prisión!) para detener las sensaciones; Albertine intenta recoger los datos más inmediatos de la conciencia, guardar la memoria del instante en el más puro estilo bergsoniano.

Liberado de trampas, incluso de las amorosas, este diario no parte con ningún miramiento o condescendencia ni hacia ella ni hacia los demás. Este diario, que se presenta como una gran muestra de lucidez y de fuerza moral, contrasta con la precariedad de la situación personal y la fragilidad física en la que se encuentra su autora.

En este preciso momento de los preparativos de la boda, el diario es también, como ha dicho Josane Duranteau ${ }^{17}$, una experiencia de "matrimonio místico": Albertine sabe que la vía hacia ella misma pasa necesariamente por Julien, igual que la de ésta a través de ella. La novia pone todo en la balanza: sus convicciones y su hipocresía, sus miserias o su orgullo, sus anhelos ... como el de ser casados por la Iglesia, a lo que habría de oponerse tan tajantemente el cura,

"Bête au fond, ce désir de passer par les sacrements... Bête mais réel, et aussi obscur que réel. On refuse. Tant pis, n'en parlons plus, contentons-nous d'en épiloguer un peu."18

Comenzado en la prisión de Amiens, en diciembre de 1958, y continuado en Soissons, El "Times" marca el tiempo de espera de Julien. Podría ser una larga carta al esposo -que le leerá después de dos años de separación-, contrapunto al mismo tiempo de la correspondencia, no en la letra o en el detalle sino en su espíritu, donde libra con mayor seguridad sus pensamientos.

El diario podría hablar de la pena y del horror de su nueva situación, de su entorno carcelario; pero, nada más lejos, como decíamos, de su intención; lo que Albertine llama con desdén "localités" o "minusseries" (pequeños sucesos del lugar, las llegadas o salidas de compañeras, los complots, las tensiones de este microcosmos penal...) no forman parte del diario, las reserva para su novela La Cavale. El diario puede ser leído sin descubrir nada sobre el decorado, sin dejarnos intuir sus costumbres.

17. Albertine Sarrazin, Journal de Prison 1959. Prefacio.

18. Idem., p. 84. 
Serían éstos algunos de los estigmas de la prisión sobre la escritura, aunque no queremos pasar por alto otros, como la lengua. El habla de la cárcel (que no es, entendemos, tanto un argot como un francés mal hablado, de imágenes clichés, sintaxis indigente y abúlico) está ausente del diario; El "Times" está escrito en una lengua clásica y depurada, influenciada a veces por el estilo hablado -tan característico de Albertine-, teñida de cierto preciosismo. Será ésta una manera más de distanciarse y de distinguirse del entorno, de emprender su particular fuga.

El diario, cuando Albertine sale de prisión, suele generalmente dar lugar al carné, al cuaderno o a la agenda. La dispersión provocada por la salida al mundo exterior o por las obligaciones del éxito termina redundando en el poder de concentración de esta autora y el ejercicio de introspección resulta una quimera. A veces también se debe a la ocupación en su obra novelesca, pero de esto ya hemos hablado.

$*$

Las cartas son también un instrumento privilegiado de seguimiento de esta fugaz Albertine, y esto tanto en el orden físico (lugares frecuentados por ella) como moral (momento anímico de la autora), y además un gran complemento del resto de sus escritos que nos permite contrastar su trayectoria autobiográfica. Todo gracias al escrúpulo de Julien y de muchos amigos que no rompieron nunca una carta. La carta es además el único escrito que no conoce interrupción importante: cuando el diario es confiscado o se detiene -como sucede misteriosamente a partir de Junio de 1966-, la correspondencia continúa, fiel a ese "otro" y a sí misma, restituyendo la autobiografía al autorretrato.

Las cartas son también, en las circunstancias especiales de la prisionera, su único vínculo con el exterior, la única posibilidad para "definirse", como Albertine reconoce en carta a Julien:

“... à mon avis c'est par les autres qu'on frôle, quelquefois, une chance de se définir... et il est bien clair qu'ici, il n'y a pas d'autres..."19

Una carta de Albertine es como un momento de fiesta; su tono es -como dice Duranteau en el Prefacio20 - a la vez "burlón", "grave", "risueño"..; siempre diverso y contradictorio; una muestra perfecta de plasticidad psicológica. El mensaje es siempre dinámico, de trazo cierto y seguro en la expresión, apenas si descubrimos un tachón. La lengua proviene del lenguaje oral tanto como del escrito.

Antes de nada conviene aquí separar las cartas propiamente dichas de los "biftons" o billetes clandestinos, que serán objeto de estudio un poco más adelante, y hacer una división, en cuanto a las primeras, según que estas vayan dirigidas a Julien o a otros destinatarios 21 .

19. Lettres à Julien, 1958-1960 (8 de septiembre de 1960).

20. Albertine Sarrazin, Lettres de la vie littéraire. Prefacio.

21. También esta división ha dado lugar a dos publicaciones diferentes, como hemos visto: Lettres à Julien, 1958-1960 y Lettres de la vie littéraire. 
En efecto, Las cartas a Julien corresponden a un registro mucho más íntimo y constituyen un modo de comunicación constante y cercano; próximas a veces al diario y no sólo porque en ellas se abandone al monólogo, sino porque se entrega a tal tarea sin tabúes y con absoluta confianza.

Dentro de esta correspondencia con Julien, habrá que distinguir los diferentes momentos, como esas primeras, que datan de la primavera del 58, cuando Albertine vive en la clandestinidad en Niza a la espera de la liberación de Julien, y que le dará a leer en mano a la salida. Estas cartas, mucho más próximas al diario íntimo, en forma de monólogo casi dialogado, presentan a una Albertine ardientemente enamorada que emprende una labor de encantamiento y enamoramiento de un Julien, inseguro y vacilante aún en sus sentimientos:

"Mais tu ignores peut-être que je sais conjuguer avec un égal bonheur la suggestion et la soumission, l'oasis et l'assoiffée. Que mon travail sur toi c'est le travail amoureux de l'artiste, et la morsure lente de la vague (...) Mon idée, c'est de mettre des bouts d'allumettes à tes yeux, pour que tu ne me voies plus telle que m'ont faite ta stupide petite bête, ton stupide petit manque de foi. Pour que tu me reconnaisses enfin" 22

Sigue una abundantísima correspondencia desde la prisión o desde el hospital (en el que se encuentra por causa del accidente de automóvil); desde la residencia de la Dra. Gogois-Myquel, en Grasse, o de los mil lugares en que debe buscar sus efectos personales, trabajar o sencillamente esperar a su marido. Más tarde, y en pleno período de celebridad, Albertine, ocupada aquí y allá por las mil exigencias de sus editores, escribirá también día a día a su marido, ironizando sobre la "mundanalidad" y sobre los personajes de la nueva vida artística y literaria en especial. Y si hasta entonces, su lengua solía ser en general esmerada -como tendremos ocasión de ver en breve- usa con libertad el argot, pudiendo esto ser entendido como una reacción ante las nuevas experiencias o como una manera íntima de evocar la complicidad del mundo clandestino del pasado, de ese viejo secreto compartido.

Pero la distinción más interesante entre sus cartas vendría sobre todo dada a nuestro parecer entre esos dos registros a los que ya aludíamos a la hora de hablar del diario: el de fuera y el de dentro de los muros de la prisión.

La prisión -y ésta es una idea que viene siendo ya habitual en nuestro análisis-, llega a distorsionar también el tono de las cartas: La comunicación que hasta ahora se producía a dos voces, espontánea y natural, "más o menos" sincera (el tema de la sinceridad en las cartas es como se sabe un tema arduo), se transforma por el efecto de uno o más intermediarios -el censor- en una conversación a tres o más voces y con

22. Lettre à Julien, 1958-1960 (16 de junio de 1958). 
unas reglas ${ }^{23}$ ahora bien precisas: brevedad y claridad serán exigidas (siendo censurado en este sentido cualquier término poco claro, de argot, o incluso escrito en verso); se prohibirá además hablar del personal de la prisión, del régimen de vida y en general de todo aquello que no tenga nada que ver con el mundo afectivo del detenido.

El resultado no es menos interesante: la lengua se vuelve esmerada y hasta preciosista, doblemente sugerente y llena siempre de imágenes. En cuanto al tono de sinceridad en las cartas debe ser éste analizado según unos parámetros particulares: de lo que se trata por una parte es siempre de aliviar al destinatario, de restar importancia a la situación y quitar preocupaciones a los seres queridos y, por otra, mantener viva la llama afectiva o del amor. En un universo degradado y degradante como éste todo sufre un importante deterioro, y el más importante quizá para el preso es la pérdida afectiva. Consciente la prisionera de tan importante riesgo, se vuelca en ellas como única posibilidad de mantener esa precaria certeza, de poseer por unos instantes ese reflejo, tanto físico -las cartas pueden ser también fuente de placer sexual-como moral del ser querido y que le llega a través del eco sonoro de la escritura. En prisión cualquier emoción se amplifica hasta lo indecible y en la mano de una artista como Albertine, las cartas de amor resultan de las más bellas que jamás hayan sido escritas. Una cuestión interesante que aquí podría también uno llegar a plantearse es la parte de responsabilidad que tiene la escritura sobre la relación amorosa.

El mensaje de la carta sufre también otro tipo de distorsión, mostrándose un tanto ambivalente: tanto Albertine como Julien dirigen sus comentarios pensando en el censor, intentando llamar su atención por ejemplo sobre su buen comportamiento, sus inquietudes, sus relaciones con el personal, etc. Si en alguna ocasión el diario fue la prueba más contundente para su condena, las cartas llegaron a servir también en un momento a la buena causa de la condenada ${ }^{24}$.

La carta es también un medio de expresión completo de la artista que la decora a veces con sus pinturas de color o tinta china (sobre todo en la etapa de Amiens) ofreciendo un resultado enormemente bello. A través de ellas también saboreamos ese espíritu irónico y burlón de la pareja que no duda en sellar sus cartas con lacre de cera, a la manera de los "Señores".

Como contrapunto a este tipo de correspondencia entre los esposos que podría decirse "oficial", existe otra de carácter clandestino, mucho más libre -aunque entre los muros de la prisión la palabra libertad nunca llega a tener un sentido pleno-, donde los amantes se explayan con toda naturalidad en esas cuestiones que no encuentran cabida en la otra: se trata muchas veces de eventualidades de orden interno, como la

23. Por supuesto que nos referimos a las normas concretas de la prisión en Francia en época de la autora.

24. En la época de Fresnes, Mme. Bourgeois había presentado las cartas de Anick a la Asistenta Social y a los abogados para demostrarles el "verdadero" fondo humano de esta prisionera. 
disponibilidad de su "estafeta" 25 , la complicidad con los vigilantes e incluso la preparación de sus fugas (que nunca llegarían a materializarse); de múltiples cuestiones personales, como la expresión de ese amor sin reservas, tan pasional y carnal; de su verdadero estado de salud, física y moral. El conjunto publicado por Pauvert, que cubre el período de junio a septiembre de 1960 (cuando Albertine y Julien compartían la misma prisión de Soissons), no es más que un tercio de los intercambiados, habiendo sido destruido el resto por medidas de seguridad o bien por alguna peripecia de sus continuos traslados. Su sintaxis es, por supuesto, muy diferente a la del resto de sus escritos: permitiéndose sus autores todo tipo de acrobacias en estos textos destinados más bien a ser oídos. Por la abundancia en ellos de códigos, de expresiones particulares y de alusiones herméticas, nos hubiera sido del todo imposible descifrar su mensaje si no hubiéramos contado para ello con la ayuda de su único intérprete válido: Julien Sarrazin.

Pero señalábamos al principio que además de Julien, la correspondencia de Albertine tenía otros muchos destinatarios, sobre todo en los momentos de su entrada en literatura que es, creemos, el más significativo ${ }^{26}$. Tenemos constancia de un gran intercambio con la madre adoptiva, "Mother" -pero no habiendo sido cedida ninguna carta por sus herederos, carecemos de cualquier otra noticia salvo la que nos brinda el diario- y del abundante e igualmente interesante -aunque en su mayoría inéditocorreo con Mme. Bourgeois (su madrina) o con Emilienne. En cambio podemos disfrutar, en una esmerada publicación, de las cartas dirigidas a la Doctora GogoisMyquel, a sus editores o a un largo etcétera de personalidades del mundo intelectual: Simone de Beauvoir, Hervé Bazin, René Bastide, entre los más significativos. Lo que más llama quizás la atención en esta correspondencia "en libertad", es la plasticidad psicológica, la capacidad de "moldearse" esta personalidad según las conveniencias de la escritora. Albertine se muestra enormemente diversa y un tanto enmascarada, bajo las fluctuaciones también del humor o de los acontecimientos del momento; se diría que le llena de placer jugar a interpretar personajes muy dispares. Así, la vemos por ejemplo en actitud de "niña buena" y "enternecedora" con la madrina, de mujer "cálida" y "sosegada" con su Doctora y amiga, "desafiante" intelectualmente y "primus inter-pares" con sus editores y las personalidades del mundo artístico -con los que además juega a dominar la sintaxis-, "implacable" con la familia Renoux o con cualquiera de sus detractores de dentro o fuera de la prisión...

Un mundo literario aparte y no menos interesante, el que se esconde pues tras su comportamiento epistolar. No hemos encontrado mejor ni más justa definición a esta actividad de Albertine que la que contiene esa misiva enviada por Julien al Procurador de la República, en el verano de 1963 cuando se vio éste privado del placer de leer las cartas de su mujer:

25. El envío se hacía casi siempre a través de alguna persona del servicio de la cantina.

26. Buena parte de esta correspondencia ha sido editada en las Lettres de la vie littéraire. 
"J'encaisse tout, pour pouvoir écrire à ma femme, pour recevoir ses lettres, et ne pas être puni quand elle vient au parloir. (...) Mon épouse m'écrit quasi quotidiennement, c'est son droit, mais ici, tout dérange. C'est pour ma femme une façon de me sortir de prison, de me faire vivre auprès d'elle, c'est une marque d'amour et aussi un exercice de style, je crois."

"Marque d'amour" y "exercice de style" ¿qué mejores términos podrían definir la correspondencia de Albertine Sarrazin?

Hasta aquí no hemos dejado de ver a una mujer dedicada a su escritura, que vive la aventura y la cuenta, que se prepara meticulosamente para su obra. A decir verdad en todos los escritos se intuye o se muestra claramente en una lograda "mise en abîme".

Donde realmente se ve la mano del artista, donde se interpreta la gran evasión es en las novelas, a las que también llama "gosses" (hijos), sin duda por colmar ese frustrado deseo de maternidad. El placer de la escritura y la vocación de novelista, Albertine las sintió desde muy temprano: los "Cahiers de Pension" nos muestran ya a esa niña de 14 años que se hace tal reflexión,

"C'est si bon de se sentir isolée et fière, avec un crayon et un vieux cahier et de faire quelque chose de nouveau avec son cerveau d'homme!"27

Años atrás ya venía incluso ensayando en pequeñas novelas de aventuras al estilo de los "cinco" o en ese "Roman sans titre" que será publicado dentro de Le PassePeine. Abundan en sus diarios o en sus cartas reflexiones proféticas sobre lo que habrá de ser su carrera:

"Un jour, je crierai ce que je suis à la face du monde; j'oublierai toutes les tares qu'a imprimées en moi cette maison de réeducation dont je me suis évadée, voici deux semaines (...) Je consacrerai à cette étude un livre entier, où mon histoire, parmi tant d'autres filles, ouvrira peut-être les yeux du vulgaire sur ce qu'est la vie d'une fillette, d'une jeune fille, d'une femme ou une maîtresse de classe, plus ou moins dévorées de passions diverses." 28

Y sin embargo cuando un periodista ${ }^{29}$ le pregunta si se considera escritora ella responderá simplemente:

$$
\text { -“Toujours pas!" }
$$

27. "Cahiers de Pension", Journal de Fresnes, p. 33.

28. "Carnets Verts", Journal de Fresnes, pp. 82-83.

29. Albertine parle. Disco Adès. (Entrevista con Jean-Pierre Elkabach). 


\section{ANTONIO BUENO GARCÍA}

Insiste cuando explica en un pequeño escrito para la prensa la intención de $L a$ raversière:

"Je disais donc que je veux bien transcrire platement la réalité et me laisser donner du "romancière" sans avoir aucun droit à ce titre."

Sobre su imaginación también ha dicho :

-“L'imagination? Je n'en ai pas."

Qué ilusión la de ésta y la de tantos otros escritores intimistas, qué interesada creencia en que es sólo la realidad la que los mueve... Estas afirmaciones tajantes no pueden por menos de sorprendernos y chocar con la propia vocación del escritor y con su postura personal frente a ella: Albertine encara en cada libro y en primera persona, una situación vivida que podría considerarse casi por entero real (la biografía nos lo atestigua) a no ser por ese deseo irreprimible en todo autobiógrafo, y descubierto en la autora, de "clarificar" una historia, de desenmascarar una intención, de perfeccionar y terminar una aventura. Esa actitud de cambiar nombres de personas o lugares, de situaciones o destinos no es menos frecuente en Albertine: la boda de Anick y Zizi (Albertine y Julien) en La Cavale no se produjo, como se nos cuenta en el relato, estando ambos en prisión -Julien estaba entonces en libertad-; lo principal de la acción se sitúa por otra parte fuera de la detención de 1961-63.

Anne y Julien no fueron apresados juntos ni en esa fecha como se relata al final de L'Astragale; tampoco existieron esas "bofetadas", nos cuenta el mismo Julien. Lou (Julien) no conocía a Albe ni fue arrestado junto con ella en la época de Fresnes como se dice en La Traversière. Y así podríamos seguir relatando un sinfín de contradicciones.

- “Ça fait plus roman!..." Diría en una ocasión Albertine.

¿Cambia esto algo el valor autobiográfico? No, pues ya contábamos con ese espíritu de reorganización, de afabulación en la novela. Reconocemos en lo esencial al mismo personaje: Anick, Anne o Albe son siempre la misma Albertine, curiosamente y sobre todo el mismo espíritu fugaz o fugitivo y la misma decisión para luchar contra el destino: Anick, de La Cavale (casada con Zizi -Julien-)es la mujer que, en el universo degradado de la prisión, marcada por su particular estigma, lon." 30

"Je suis vraiment harnachée pour arriver en taule ce soir: oposum et panta-

intenta continuamente su evasión ( su "cavale"), evasión que será no ya tanto física -pues fracasa en el intento- como moral:

30. La Cavale, p. 11. 
"Minuit sonne: j'essuie mes yeux à la berlue, allez hop, en selle. Les beffrois de la ville entrelacent leurs arabesques, comme les cloches d'un mariage; et moi, bien avant que le jour se lève, je commence à imaginer mes étrennes." 31

Anne en L'Astragale salta el muro de 10 metros que la separa de la libertad, del amor también,

"Le ciel s'était éloigné d'au moins dix mètres."32

y sufre las penosas consecuencias de un universo hostil (se rompe el "astrágalo", un hueso del pie; sufre las mezquindades de la sociedad, sobre todo marginal; le resultará casi imposible moverse con muletas, vivir de escondite en escondite, esperar a Julien -su amor salvador-, en una cama de hospital o de "ocasión"...) y termina estoicamente aceptando sü destino fatal,

"N'importe, je marche: précédant le flic, je descend l'escalier, en claudiquant à peine."'33

Albe, en La Traversière (continuación lógica y cronológica de La Cavale) ha conseguido casi la liberación total -tan sólo le quedará una pequeña pena por cumplir por el robo de una botella de whisky- cuando se enfrenta a otra más sutil evasión, la de su presente y su pasado: la protagonista analiza la frustrante experiencia de su niñez, la relación con sus padres adoptivos,

"Nous sommes trop vieux..."

"C'est tout ce qu'il parvenait à sortir mon père adoptif." 34

las enormes dificultades de la salida, de la nueva vida: la eterna espera de Lou (Julien) que trabaja fuera de casa; la insoportable condición de la vida en trío ${ }^{35}$; la demora del editor y al final, esa crisis tan natural en todo escritor,

"N'y a-t-il plus un seul cahier d'écolier chez le marchand, plus une seule aventure à vivre dans les cinq continents, dans le ciel ni dans les océans, plus rien nulle part à connaître, à créer, à écrire, le Bic aurait-il la tremblote, serait-il 'trop vieux' lui aussi?"36

31. La Cavale, p. 506.

32. L'Astragale. París: Pauvert, 1965, p. 5.

33. Idem, p. 192.

34. La Traversière, París: Pauvert, 1966, p. 7.

35. Albertine y Julien se instalaron un tiempo con Maurice, un amigo ("l'Oncle" de L'Astragale).

36. Idem, p. 317. 
Las tres novelas que presentan, como decimos, una idéntica andadura y que llevan incluso -lo habíamos comentado ya anteriormente- una construcción "en abîme" de la propia novela (pueden considerarse como la historia también de un manuscrito, un libro dentro de un libro) son por lo demás de una curiosa antítesis. Conviene recordar antes de continuar que La Cavale es un relato de prisión entre dos períodos de libertad. L'Astragale, el de una evasión entre dos períodos de prisión y La Traversière, un relato de libertad después de un largo período de prisión. De los tres libros, tan sólo $L a$ Traversière fue escrito fuera de los muros de la prisión, una vez conseguida la plena libertad e incluso la popularidad literaria. Esto a simple vista no querría decir nada si no fuera por la curiosa variación que experimentan desde el punto de vista formal y de contenido los tres manuscritos. Se produce continuamente una alternancia de luz y noche, expansión y concentración, tensión y distensión, como en general sucede en la existencia de un "reincidente".

En efecto, la primera de las tres novelas, La Cavale (aunque segunda en orden de publicación) podría considerarse como un relato "nocturno" en el sentido de que sigue el camino de una introspección hacia lo más profundo del ser; con mil reflexiones sobre su experiencia personal, a la manera del diario íntimo, del que toma las formas. La concentración se siente también a nivel de la narración: Albertine en La Cavale se libera de una parte de su vida que -a excepción de algunos hechos episódicos como alguna pequeña alusión a la infancia, el primer arresto, la prisión de Fresnes, por ejemplo- se centra en su propia experiencia carcelaria de los años 1961 a 1963. La soledad de la celda -a pesar del hacinamiento que conociera en la prisión de Versalles, donde por entonces se encontraba la autora- contribuyó necesariamente a la concentración personal de la escritora. A lo largo de todo el libro se respira también cierta tensión, derivada sobre todo del propio clima de la vida carcelaria, tan bien creado por esta autora que emprendió la andadura de este argumento -téngase en cuenta- con la idea de hacer un reportaje sobre la situación en prisión ${ }^{37}$; la descripción de la atmósfera carcelaria, con la continua mirada de los guardianes, la promiscuidad de las condenadas, sus disputas y vejaciones, sus largos tedios, es recogida como a hurtadillas por esta genial observadora en el "lugar del crimen" y siendo sacada por mediación del abogado.

El empleo constante de argot se explica por el lugar importante que ocupa en los diálogos de las prisioneras, de los que la obra es vivo reflejo.

El peso de la realidad sobre la ficción parece también más importante en esta obra de reclusión donde la vida cotidiana es la auténtica aventura. En el argumento de $L a$ Cavale hay poco lugar para la imaginación a no ser la continua idea de la "cavale" misma.

Como resultado, el relato parece dar también la sensación de no poder salir de sí mismo, de tropezar constantemente con los mismos escollos, de dar vueltas en círculo,

37. La idea le había venido a través de una compañera de detención, que se encargaría también de hacer las fotos para sacarlo a la luz en la prensa. 
como hace el mismo recluso en su celda. Puede que resulte algo largo (y ello a pesar de que la autora lo redujo casi a la mitad, siguiendo el consejo de Simone de Beauvoir, su primera lectora), porque para el autor mismo su aventura es muy difícil de terminar.

En L'Astragale, historia que se sitúa en el exterior -a pesar de haber sido elaborada también en prisión- el empleo del argot es curiosamente más restringido por apartarse la protagonista del círculo de la prisión. El argumento: una historia de evasión y de amor, en un tiempo muy preciso y limitado -el de su vida clandestina tras la fuga de Doullens- se concentra en este preciso espacio de tiempo, y apenas si encontramos alguna breve incursión en el resto de su vida pasada. El relato es mucho más corto que el anterior, como si el tiempo de fuera pasara vertiginosamente. El porcentaje de imaginación frente a los hechos de la vida real sigue siendo como en La Cavale un tanto deficitario. Seguimos apreciando la concentración del autor y también la de su escritura. A través de ella se respira también cierta tensión por una dramática sombra que planea a través de ella: la evadida de la justicia no puede dejar de vivir en la obsesión de ese día más o menos cercano en que volverá a ser capturada.

Esa tensión a la que aludimos y que sería uno de los más claros ingredientes en las obras de prisión de Albertine, parece haber desaparecido por completo en La Traversière.

La novelista se entrega aquí con menos rabia y mucha más tranquilidad a su personal confesión sobre su vida presente y pasada. Sobre esta misma cuestión, Albertine declarará también en el momento de la publicación del manuscrito :

"Je ne l'ai pas écrite dans les mêmes conditions. Je ne pouvais pas l'écrire avec la rage avec laquelle j'avais écrit les deux premiers en prison. J'étais dans mon petit bureau, au chaud, je n'avais pas faim.(...)"38

Curiosamente el universo carcelario parece casi desterrado de los presupuestos de esta novelista que dice haber hablado ya suficientemente de él.

No cabe duda de que Albertine se muestra también en La Traversière mucho más segura de sí misma y feliz -fruto de su libertad y de su reconocimiento literario y social- y de que el tono "duro" tiene ya otro sentido...

"Castelnau(*) m'a dit . "On dirait que ce bouquin est écrit avec l'indulgence du bonheur". Il m'a même demandé de le durcir. J'ai remis, sans trop me forcer, par ci par là, des petits bouts de colère. Castelnau avait raison. Au début, j'écrivais un peu sur le ton: "Chers lecteurs de "La Cavale", je vais vous raconter la suite." 39

* Director literario de Ediciones Pauvert en la época.

38. Pierre Déméron, "La grande évasion d'Albertine Sarrazin", Candide, 21 de Noviembre de 1966, pp. 35-37.

39. Ibidem. 
Mucho más libre e inquieta, la novelista se ejercita en su tarea de artista, intenta apartarse más del relato, ahondar en la fantasía: había intentado la tercera persona e incluso se había atrevido a presentar a Lou (Julien) muerto; aunque estas fórmulas no serán del agrado del editor y deberá desecharlas de inmediato.

El alboroto formado en torno al personaje, las penosas obligaciones del éxito, la responsabilidad del siempre temido "segundo libro" -recuérdese que los dos primeros aparecieron a la vez- junto con las presiones del editor contribuirán también a descentrar la inspiración de esta mujer, que llegará incluso a añorar la dulce calma de la prisión y a necesitar su recóndito espacio ${ }^{40}$. Tras un obligado período de descanso y en un tiempo récord, Albertine sacará a la luz La Traversière, el último de sus "gosses" y el libro ansiosamente esperado por todos aquellos que podían creer que su éxito sólo era fruto del escándalo y de la curiosidad malsana frente al mundo de la prisión.

El libro aparece escrito en una lengua más depurada, aunque no por ello menos personal; veraz como el primero, y algo más redentor si cabe, por haber exorcizado en él una mayor parte de su pasado. Albertine había logrado evadirse otra vez.

Podrá decirse en conclusión que la experiencia autobiográfica de Albertine fue sin lugar a dudas singular, que ésta acompañó siempre su carrera literaria y formó una unidad con su personalidad. Escribiendo su vida, Albertine quiso sobre todo exorcizar la realidad, desarmarla de todo su mal, romper su desoladora incomunicación. La autobiografía, se sabe, es uno de los campos más privilegiados del conocimiento humano y por añadidura de la personalidad del escritor o del artista. Si la empresa del autoconocimiento choca ya con mil obstáculos en el camino hacia la verdad, podemos imaginar con cuántos más no lo hará si, como en este caso, la experiencia se desarrolla en un círculo de fuerza y de represión como es el universo de la prisión.

Los diferentes escritos autobiográficos, sean cartas, diario, novelas, etc., deben analizarse siempre en su contexto y teniendo en cuenta las leyes precisas del género y la mecánica propia de su escritura; deberemos añadir a éstas las propias de la situación personal o social del autor, como en el presente caso, las del universo penitenciario o de la clandestinidad, que en el orden externo estarán sin duda en consonancia con la sociedad y la época que le toque vivir ${ }^{41}$ y que en el interno nunca sufrirán variación en la historia de la Humanidad: la reclusión y la condena alienan siempre al ser humano.

El poder de concentración e introspección es primordial en esta experiencia y aventura hacia lo más profundo del ser. La prisión se erige en universo protector de esta extraordinaria tentativa. La escritura ha vuelto una vez más a recompensar, le ha dado a la prisionera la llave hacia su libertad, dejándonos la prueba a nosotros de que con ella consiguió su verdadera evasión.

40. Su marido le construirá una pequeña celda en su casa de Cevennes para que pueda seguir concentrándose.

41. El reglamento de la prisión varía de una época a otra, según la ideología dominante en la sociedad y con efectos diferentes sobre el condenado, como demuestra Michel Foucault (Surveiller et punir: naissance de la prison. París: Gallimard/NRF, 1975). 